\title{
Percutaneous Ultrasonography as Imaging Modality and Sampling Guide for Pulmonologists
}

\author{
Jos A. Stigt ${ }^{a}$ Harry J.M. Groen ${ }^{b}$ \\ ${ }^{a}$ Department of Pulmonology, Isala Klinieken, Zwolle, and b Department of Pulmonology, University Medical \\ Center Groningen, Groningen, The Netherlands
}

\section{Key Words}

Interventional ultrasonography · Interventional pulmonology · Chest ultrasound · Pleural effusion · Thoracic tumours - Transthoracic sonography · Lung cancer diagnosis · Biopsy

\begin{abstract}
Ultrasound (US) imaging is gradually progressing into common practice in contemporary pulmonology. Its main applications are to determine the presence and amount of pleural effusions and to guide subsequent treatment interventions. Guidelines recommend the use of US for these indications. Training programs are organized and competency levels are formulated. Image guidance with US to obtain specimens for pathologic and/or microbiological analysis is less extensively practiced by pulmonologists but it is an important tool for tumour staging and diagnosing diseases. Lung tumours in contact with the pleural surface, pleural thickenings, mediastinal tumours and chest wall tumours are conceivable indications for pulmonologists to approach with the help of US visualization. Moreover, sampling of chest disease-related extrathoracal lesions may also be regarded as the working field of the pulmonologist. For example, supraclavicular and axillar lymph node metastasis, and also soft tissue and bone metastases, are lesions encountered during dissemination tests. US-guided biopsy provides not only a diagnosis, but
\end{abstract}

also gives information on the stage of disease in sometimes inaccessible primary lesions. US-guided sampling increases diagnostic efficacy and safety and enables very precise performance of fine-needle aspirations as well as tissue core biopsies.

(c) 2014 S. Karger AG, Basel

\section{Introduction}

Although more and more pulmonologists apply ultrasound (US) in their daily practice, it is still not recognized everywhere as a standard diagnostic modality suitable for respiratory professionals. This is remarkable since considerable published clinical and scientific evidence show the advantages of the incorporation of US in regular pulmonology. In this respect, respiratory physicians should be inspired by innovations in other disciplines, such as cardiology, urology and gynaecology.

Previous articles in this series: 1 . Herth FJF, Kreuter M: Ultrasound in pulmonology. Respiration 2014;87:1-2. 2. Gompelmann D, Herth FJF: Role of endobronchial and endoscopic ultrasound in pulmonary medicine. Respiration 2014;87:3-8. 3. Kreuter M, Mathis G: Emergency ultrasound of the chest. Respiration 2014;87:89-97. 4. Reissig A, Copetti R: Lung ultrasound in community-acquired pneumonia and in interstitial lung diseases. Respiration 2014;87:179-189.

\section{KARGER}

E-Mail karger@karger.com

www.karger.com/res
(C) 2014 S. Karger AG, Basel

0025-7931/14/0876-0441\$39.50/0
Jos A. Stigt, $\mathrm{MD}, \mathrm{PhD}$

Department of Pulmonology, Isala Klinieken

Dokter van Heesweg 2

NL-8025 AB Zwolle (The Netherlands)

E-Mail j.a.stigt@isala.nl 
The practical advantages of US are clear and provide a low barrier to start performing ultrasonography. Beneficial features of US are the absence of ionizing radiation, the mobility of equipment, and low purchase and operation costs.

This review is the final part of a thematic review series covering the main aspects of US applications in pulmonology [1-3]. Technical principles and aspects of US will not be repeated in this text as they have been described extensively in several recent reviews [4-8]. The two most established indications for thoracic US - characterization and identification of pleural effusions and guidance of aspirations and biopsies - are discussed in this paper. Recently published and clinically relevant information is assembled as an update of the aforementioned reviews.

\section{US and Pleural Effusion}

\section{Visual Analysis}

Ultrasonography visualizes the accumulation of fluid between visceral and parietal pleura very well. Effusions appear as non-echogenic areas and demarcate the hyperechogenic diaphragm and contiguous liver and spleen areas. The echogenic features of effusion can be subdivided into anechoic, complex non-septated, complex septated and homogenously echogenic. Anechoic means total echo-free space between the parietal and visceral pleura, and is seen in transudates and exudates (fig. 1). In a complex non-septated effusion there is echogenic material inside an anechoic effusion, whereas floating fibrin strands characterize complex septated effusions; both are always exudates. Finally, homogenously echogenic spaces in the pleura cavity are also always exudates and are seen in haemorrhagic effusions and empyema $[9,10]$. The ultrasonographic appearance of a pleural effusion can be helpful to a certain extent in distinguishing malignant from non-malignant aetiology. Pleural nodules, pleural thickness of more than $10 \mathrm{~mm}$ and the swirling sign (floating hyperechogenic particles) suggest a malignant effusion, whereas the finding of a lung air bronchogram and septation points to non-malignant disease [11]. Different investigators have reported high diagnostic performances for the diagnosis of pleural effusions based on ultrasonographic characteristics only $[11,12]$. The overall sensitivity and specificity for all diagnoses was 80 and $83.6 \%$, respectively, in a study of 133 patients [11]. The positive predictive value for malignancy was 82.8 and $100 \%$, and the negative predictive value was 81.2 and $79 \%$ in two studies of 66 and 33 patients, respectively $[11,12]$.

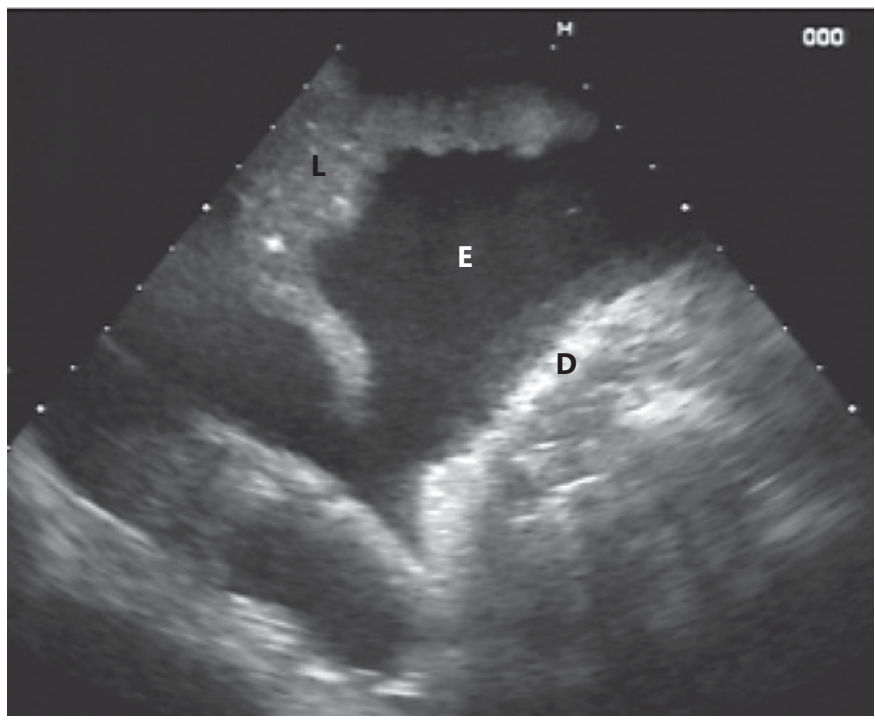

Fig. 1. Ultrasonography in a peritoneal dialysis patient showing a massive effusion (E) causing atelectasis of the lung (L) by compression. The diaphragm (D) becomes clearly visible through the effusion.

Septations in pleural effusions are better visualized with US compared to standard chest radiography or even computed tomography (CT) [13]. However, a correlation between US appearance and Light's criteria for empyema, presence of pus or the need for surgical intervention was not demonstrated in 36 patients with proven parapneumonic effusion or empyema [14].

A small amount of effusion is sometimes hard to discriminate from pleural thickening with US. Changes of lesion shape or moving structures upon breathing excursions are indications of effusion as well as turbulent Doppler signals during respiratory or cardiac movements (fluid colour sign) [15].

US images provide an easy and cheap tool for experienced operators to have a first impression of different disease processes. To obtain basic (level 1) competence, the Royal College of Radiologists recommends at least one session of practical training per week over a period of no less than 3 months with approximately five scans per session [16].

\section{Quantification of Pleural Effusions}

Very low quantities of pleural effusion can be identified with ultrasonography, which is superior in this respect to clinical examination or chest radiography [17]. Estimation of the volume of effusions is feasible with US, but it is more relevant in the intensive care setting than 
Fig. 2. Biopsy attachments mounted on a US probe. a 20-Gauge lumbar needle. b 14-Gauge TCB needle.
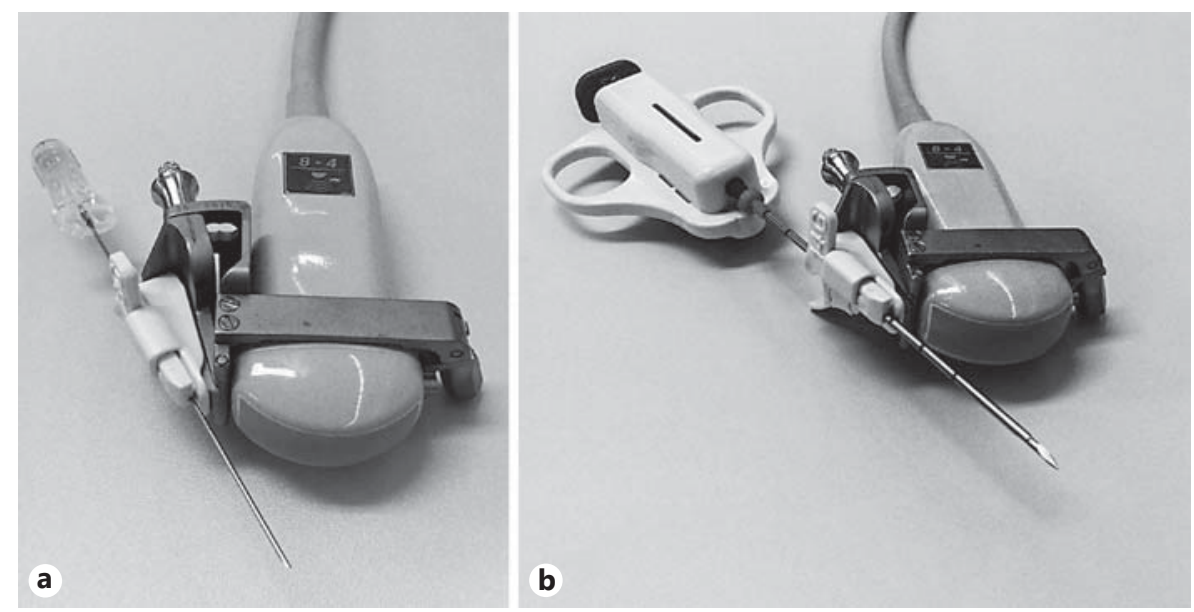

for diagnostic purposes. A significant correlation between the expiratory interpleural distance measured at the thoracic base and the fluid volume was demonstrated in critically ill patients. At least $800 \mathrm{ml}$ of fluid was produced with thoracentesis when the interpleural distance was more than $45 \mathrm{~mm}$ on the right side or more than 50 $\mathrm{mm}$ on the left side [18]. Comparable results were reported in mechanically ventilated patients. A distance between lung and posterior chest wall of $50 \mathrm{~mm}$ or more (on either side) predicted a drained volume of at least $500 \mathrm{ml}$ [19]. A quantification of free-flowing pleural effusions, based on ultrasonographic findings, has been proposed recently. In this classification, the effusion is divided into six grades characterized by the degree of lung collapse, visibility of landmarks and number of intercostal spaces involved [20].

\section{Guidance in Chest Drain Placement}

International guidelines recommend the assistance of US in placing chest tubes because it increases safety and success rates [21]. Compared to thoracentesis there is not so much evidence for the use of ultrasonographic imageguidance for chest tube drainage. There are no reports available comparing image-guidance with other treatment strategies. However, several studies have demonstrated series of patients with successful US-guided chest tube placements, especially when effusions were loculated [21]. Moreover, it is reasonable to extrapolate safety data of pleural aspiration to drainage procedures [21-24]. Consequently, it is expected that US guidance results in less complications, particularly pneumothorax and erroneous drain placement, in the treatment of pleural effusions, especially in loculated effusions or empyema.
Another safety issue is the prevention of bleeding during the drain insertion. US enables visualization of the course of an aberrant or intercostal vessel which is advantageous to determine the best location for drain insertion. It is well known that more vulnerable intercostal arteries are found near the spine, disappearing gradually behind the overlying rib in the axillar plane [25]. A sensitivity of $86 \%$ for US to detect vessels within the intercostal space was demonstrated in a study in 50 patients [26]. US is therefore regarded as an adequate tool to screen for vulnerable vessels before starting the drain insertion procedure.

Recently, information has been published on the extent of the use of US in guiding chest tube drainage. An audit performed in 2010 by the British Thoracic Society revealed that in $77 \%$ of pulmonary departments a US machine is available, and in 34 of the 58 surveyed respiratory departments at least one member was trained to level 1 competence [27]. Furthermore, a survey performed in 2011/2012 amongst respiratory physicians from Australia and New Zealand reported that two thirds of respondents do localize pleural effusion with the aid of US before thoracentesis or chest tube drainage. The reasons for not using US included a lack of expertise and availability of equipment, and this illustrates the existing gap between common practice and guidelines [28].

\section{US as a Sampling Guide}

\section{General Remarks}

Interventions are performed by pulmonologists, intervention radiologists and surgeons. In case more special- 
ists are involved, a good multi-disciplinary consultation system should be operational. Quality control is important to improve the procedures and a continuous feedback of different quality aspects of the provided samples from pathologist to the operator is essential for optimizing diagnostic procedures.

The real-time mode of US is the most important quality in guiding aspirations or biopsies. Lesions can be sampled under direct vision, including details of surrounding structures. This feature provides a high degree of safety especially when biopsies are taken from lesions near vascular structures or in the lung. Although many authors prefer to perform biopsies with the 'free hand' technique, biopsy attachment devices mounted on the transducer can ease the diagnostic procedure for the operator by moving the needle in the US plane (fig. 2).

Biopsies and aspirations are performed under local anaesthesia of overlying skin and parietal pleura. Fine-needle aspirates (FNA) are used for cytologic analysis and tissue-core biopsy (TCB) needles are generally used to obtain histologic material. The results of transthoracic US-guided FNA were compared with US-guided TCB in 123 lesions from different origins. FNA and TCB yielded a diagnosis in 82 and $76 \%$ of patients, respectively. FNA performed better in patients with lung cancer ( 95 vs. $81 \%$ ) but TCB was better in diagnosing benign lesions and noncarcinomatous tumours [29]. In our own series, 22-gauge spinal needles were used for aspiration because of their longitude [30]. Compared to injection needles, for example, there is more freedom to move in the US plane when guided by the attachment device. By performing multiple needle punctures in different directions, a lot of cytological material can be obtained. For adequate histologic biopsies, we acquired a lot of experience with 14-gauge TCB needles to obtain enough tumour tissue for histological evaluation and mutation analysis.

\section{Pleural Thickenings and Effusions}

Thoracentesis and US

US imaging qualities are excellent for pleural effusions. The real-time visualization and coloured Doppler effects enable very accurate and safe sampling of effusions for diagnostic purposes. The results of diagnostic thoracentesis improve when performed under the guidance of US. The rate of accurate aspiration sites was increased by $26 \%$ when US was used in comparison to physical examination in a study of 67 patients [23].

Injury to organs or adjacent vessels by erroneous punctures can be avoided by using US. The complication rate of diagnostic and/or therapeutic thoracentesis under US

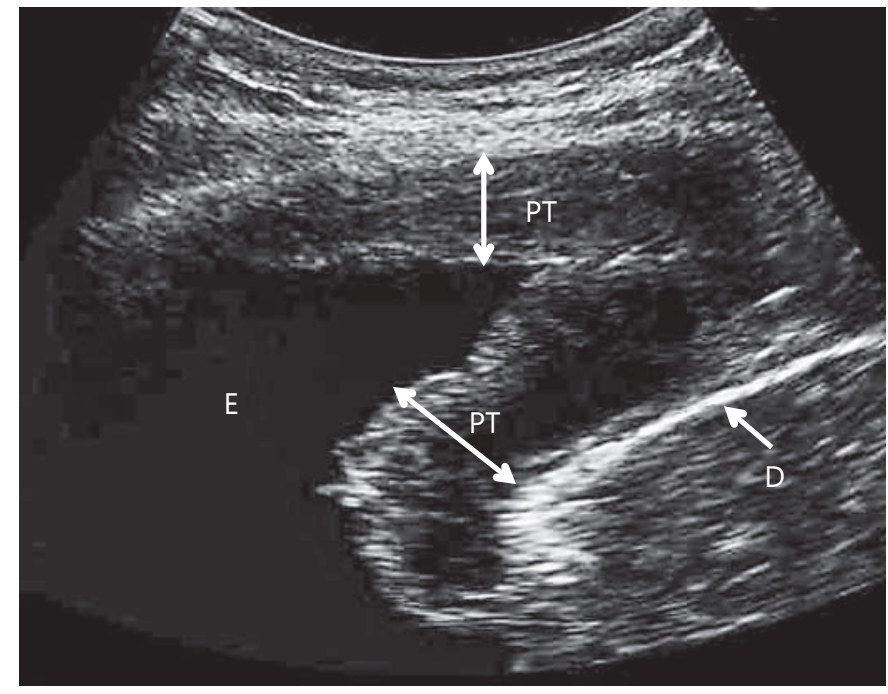

Fig. 3. US image of extensive diffuse pleural thickening (PT) in a patient with small-cell lung cancer. $\mathrm{E}=$ Effusion; $\mathrm{D}=$ diaphragm.

guidance is very low and was reported as $2.5 \%$ for pneumothoraces in a retrospective analysis of 941 procedures, requiring chest tube drainage in $0.8 \%$ of patients [24].

A meta-analysis of 24 studies described pneumothorax rates in a total of 6,605 thoracenteses. With the use of US, a $4 \%$ pneumothorax rate was estimated versus $9.3 \%$ in thoracenteses performed without the aid of ultrasonography [22].

\section{Pleural Thickenings and US}

Pleural thickenings are usually defined local lesions larger than $3 \mathrm{~mm}$ in width on the visceral or parietal pleura (fig. 3). Ultrasonography enables localization and estimation of pleural thickenings to determine the optimal site for tissue biopsies. Closed pleural biopsies (CPB) with Abrams pleural needles and TCB are both used to obtain histologic samples from the parietal pleura, and the latter has the advantage of being performed in real-time mode with US.

\section{US Guidance and CPB (Abrams Biopsies)}

With $\mathrm{CPB}$, adequate diagnostic material is obtained in less than $60 \%$ of patients with a malignant effusion [31]. If successful in cases of malignancy, the technique provides tissue samples enabling morphologic description and molecular analysis. The diagnostic success depends on the optimal localization of disease. For instance, malignant deposits are usually located on the lower parietal pleura and tuberculosis has a more generalized distribu- 
tion. In cases of significant disease deposits, such as in tuberculosis or heavy pleuritis carcinomatosa, US guidance of CPB did not improve the diagnostic yield significantly [32].

The diagnostic performance of US-guided Abrams biopsies was compared with US-guided TCB in a randomised study in patients with pleural tuberculosis. More pleural tissue was found in $\mathrm{CPB}$ (91\%) compared to TCB (78.7\%), and the diagnostic sensitivity for $\mathrm{CPB}$ was superior ( 81.8 vs. $65.2 \%$ ), again explained by the generalised pleural distribution of tuberculous granuloma [33].

\section{US-Guided Tissue-Core Pleural Biopsies}

Several studies have demonstrated improved results of TCB for pleural thickenings when guided by ultrasonography $[31,34]$. In a series of 52 patients with malignant pleural mesothelioma (MPM) diagnosed with US-guided biopsies, a diagnostic accuracy of $80 \%$ was reported [35]. The presence or absence of pleural effusion was not described in these patients, unfortunately, as effusion might hinder the ultrasonographic estimation of pleural thickening.

When there is little pleural effusion or when effusion is absent in MPM, US is an easy tool for visualizing the pleural thickening for safe and effective sampling with TCB, also resulting in a diagnostic accuracy of $80 \%$ [36]. A sharp demarcation between lung and pleural thickening enables a precise approach of the needle (fig. 4). No doubt the success rate of US-guided TCB depends on the thickness of the lesion, as demonstrated by a $100 \%$ success rate in 10 patients with an MPM of at least $20 \mathrm{~mm}$ in width [37].

\section{CPB Compared to Pleural TCBs}

A small study comparing traditional blind $\mathrm{CPB}$ with the Abrams needle and US-guided TCB demonstrated an improvement of diagnostic results with image guidance, especially in patients with tuberculous pleuritis [34]. In a study consisting exclusively of patients with tuberculous pleuritis, US-guided CPB had a significant higher sensitivity compared with US-guided TCB (82 vs. 65\%) [33].

\section{US for Thoracoscopy}

The significance of US for thoracoscopy is limited. Of course, US could be used to localize the place of insertion of the trocar with the patient in position for the procedure. Identification of septation, adherences, position of the diaphragm and masses are helpful thereby. Some authors use the ultrasonographic sliding sign of lung tissue to the predict collapsibility of the lung when there is no effusion for a safe and guided introduction [7].

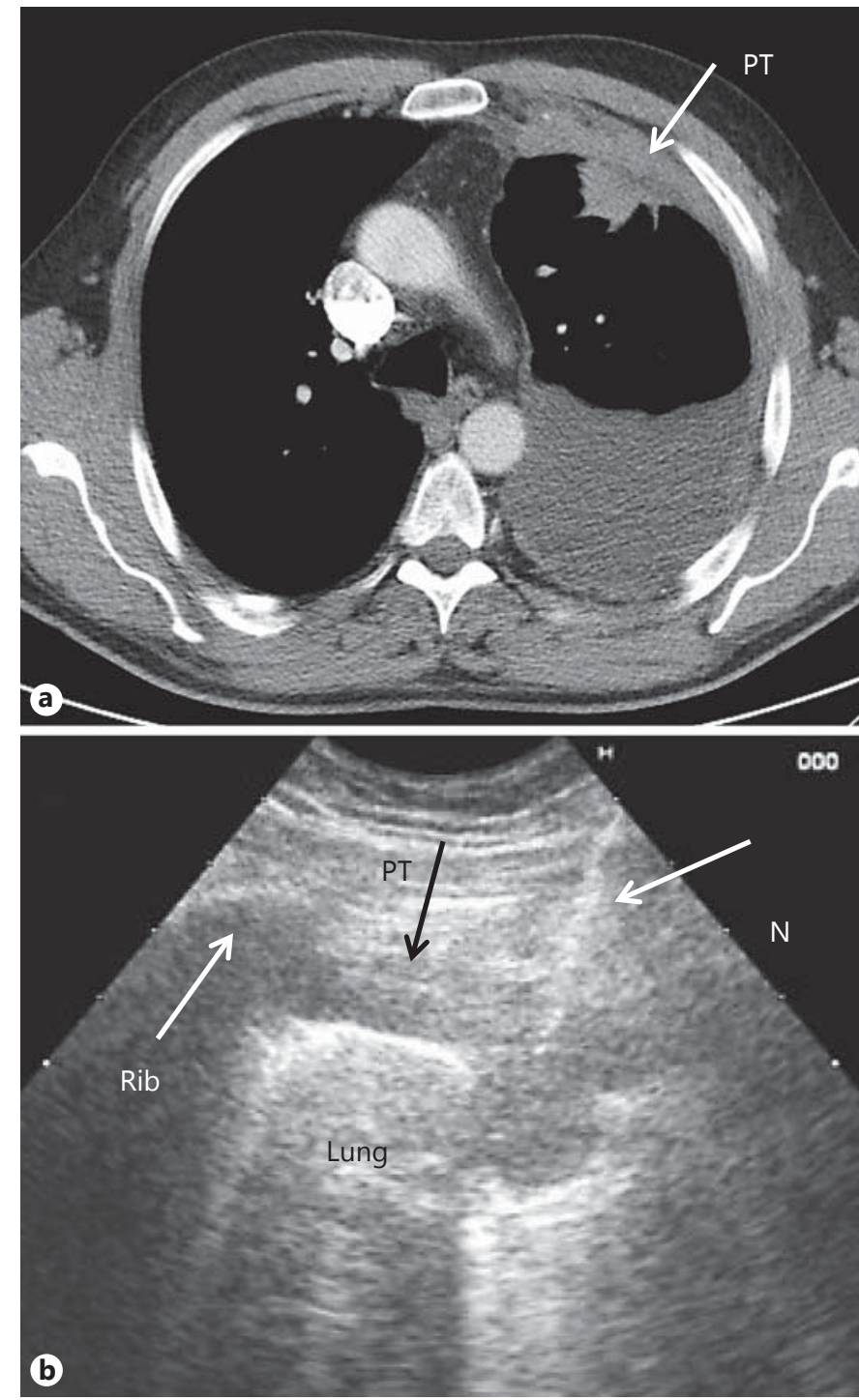

Fig. 4. Mesothelioma diagnosed with TCB. a CT showing a pleural thickening $(\mathrm{PT})$ anterior with pulmonary consolidation. b Ultrasound image showing a needle in a PT. Note that the biopsy was taken from a PT not lined by effusion. $\mathrm{N}=$ Needle 14-gauge.

\section{Pulmonary Lesions}

Pulmonary lesions in contact with the pleura can be diagnosed under US guidance, as shown in figure 5. Invasion and adherence to the pleura or an independent movement of the pulmonary lesion from the pleura are important findings visualized by the dynamic characteristics of US. Sometimes small lesions partially hidden by a rib will only become visible while breathing deeply. US should not be used for intrapulmonary lesions not in contact with the pleura. 

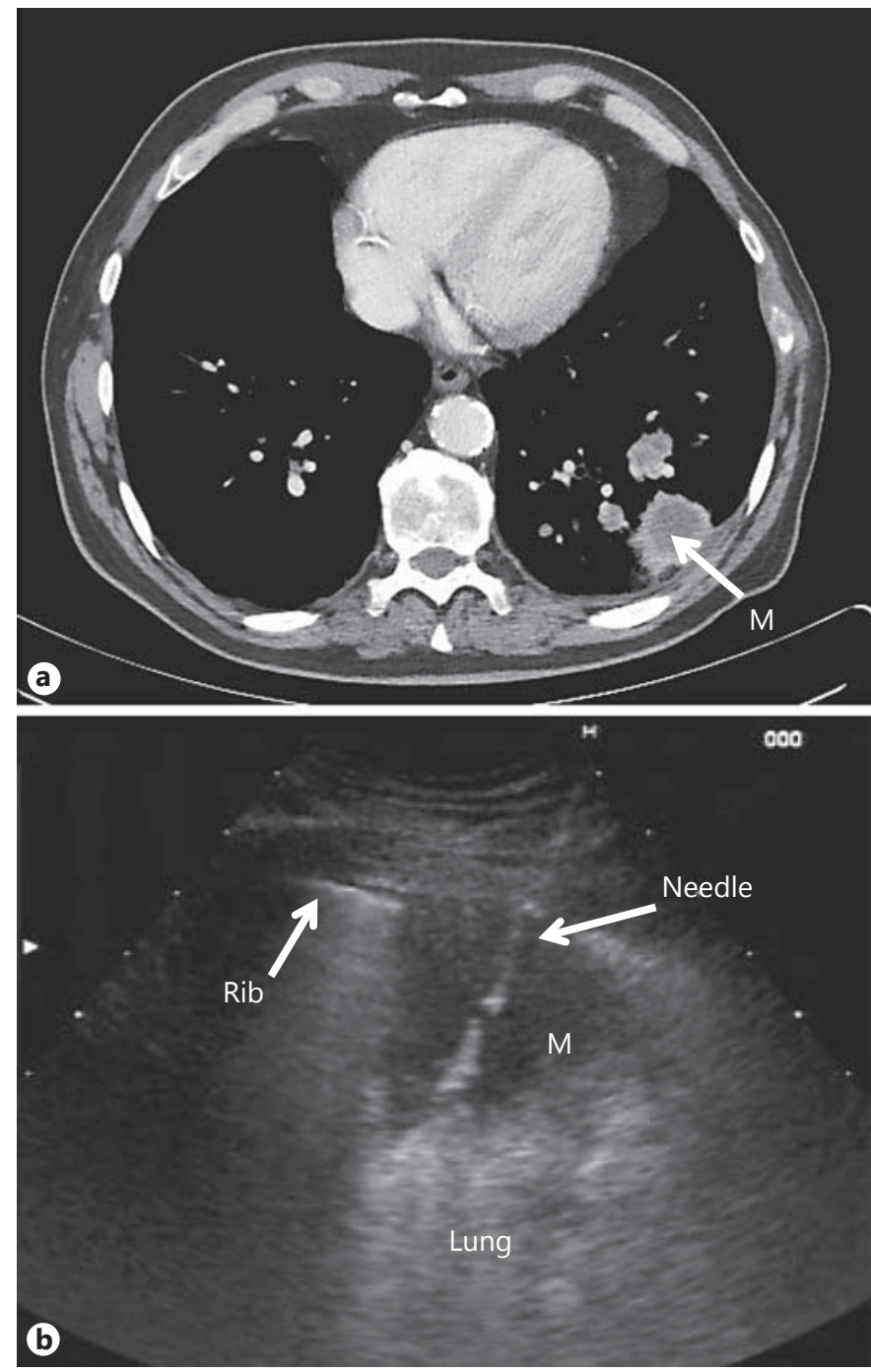

Fig. 5. Adenocarcinoma. a CT showing an intrapulmonary mass (M) in contact with the pleura. b US image showing a 14-gauge TCB needle entering the mass.

Diagnostic accuracy rates for transthoracic US-guided FNA of up to $99 \%$ are reported in lesions visible with US [38]. Comparable rates are described for US-guided TCB, varying in several studies between 84 and 95\% [39]. Nevertheless, differences in diagnostic performance between US-FNA and US-TCB have been observed. Success rates are associated with the kind of diagnosis, with some requiring more tissue and tissue architecture instead of single cells. FNA performs significantly worse compared to TCB in non-carcinomatous malignancies and benign disease [40]. Likewise, the performance of US-guided FNA is inferior in metastatic cancers in comparison to TCB [41].
Complications are rare and do not differ between USguided TCB and FNA. Pneumothorax is seen most frequently, ranging between 0 and $8 \%$, whilst for both techniques rates of haemoptysis and hemothorax are reported as being between 0 and $1 \%$.

When comparing US with CT as an image-guiding modality, differences are not clear provided that lesions are in contact with the pleura. A comparable diagnostic accuracy of US- and CT-guided biopsies was reported recently in 273 patients (103 analysed with US and 170 with CT). US-guided procedures took significant less time to perform (median 321 vs. $556 \mathrm{~s}$ ) and caused less complications (5.8\% after US-guided biopsies and $14.7 \%$ pneumothorax after CT) [42]. Not surprisingly, the success rate is dependent on the length of the lesion-pleura contact arc [39].

Even when a tumour is not pleural based, it is sometimes possible to obtain tissue under US guidance, provided there is pulmonary collapse or post-obstructive pneumonitis in between. A diagnostic yield under these circumstances of $74.2 \%$ in a series of 31 patients was described without any complication [43]. Optimization of results of US guidance is theoretically possible with contrast enhancement. With this technique, anechoic regions in a lesion suggest necrosis. These regions of the target are better to avoid when taking biopsies in order to obtain material from more vital parts. A group of 62 patients, all with lesions visible with US, were biopsied with contrast enhancement and compared with 59 patients biopsied without contrast enhancement. This study demonstrated a significant difference in the diagnostic accuracy in favour of the contrast-enhanced group (93.6 vs. $78.0 \%$ ) [44]. Although apparently promising, this technique is not widely applied.

\section{Mediastinal Tumours}

Mediastinal tumours are covered by sternum and ribs that lie close to each other. This has important consequences for US visibility and accessibility for ultrasonography-guided tissue sampling. Success depends on the tumour size and degree of positioning in the median line. Furthermore, the internal mammary arteries lie close to the lateral sternal borders and should be taken into account when needles are advanced in this region. When the tumour has a more eccentric localization and provided it is in contact with the chest wall, biopsies can be readily taken, and are easy and safe [45] (fig. 6).

Histological biopsies are mostly required for masses in the anterior mediastinum. Therefore, the best results are obtained with US-guided TCB. A study in 55 mediastinal 

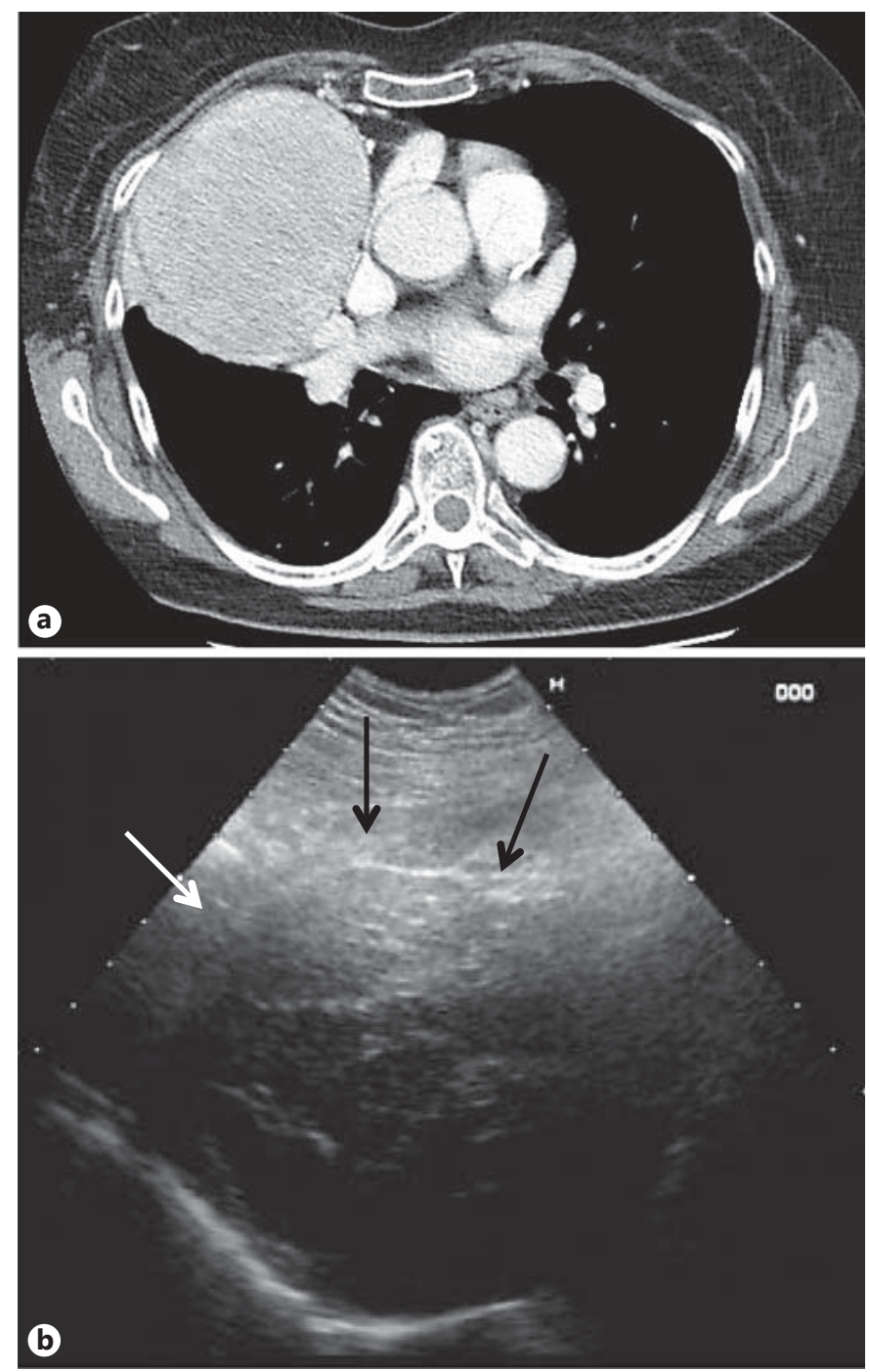

Fig. 6. Thymoma. The eccentric location facilitates US-guided TCBs. Note that tumour heterogeneity is visualized better with US (a) than with CT (b). The arrows indicate the tumour boundaries. b US image showing a needle in a pleural thickening. Note that the biopsy was taken from a pleural thickening not lined by effusion.

tumours showed a diagnostic accuracy of US-guided TCB of $89 \%$ [46]. In a more recent series of 47 patients, all were diagnosed with US-guided TCB, including all those with thymoma and lymphoma [45].

However, FNA may be sufficient for carcinomas, but for relevant differential diagnostic considerations like thymoma, malignant lymphoma, sarcoma, teratoma and also benign diseases, histology is required [47]. This was illustrated by a comparative study in 29 mediastinal tumours showing superior diagnostic accuracy of US-guid- ed TCB (100\%) over FNA (46\%) [41]. A more recent study in 50 patients confirmed these observations with diagnostic accuracies of $100 \%$ for TCB and $63 \%$ for FNA. The diagnostic procedures were complicated by pneumothoraxes requiring drainage in $2-4 \%$ [41, 45, 47, 48].

A more stepwise but single-session strategy, with rapid on-site evaluation of FNA, followed immediately by TCB when a carcinoma or tuberculosis could not be diagnosed was described in a study of 45 patients with mediastinal masses. This approach was successful in $93.3 \%$ of patients while no complications were reported [49].

\section{Supraclavicular Nodes}

Supraclavicular lymph nodes are frequently involved in thoracic malignancies and are important for prognosis and therapeutic decisions. In lung cancer patients, US examination of supraclavicular nodes is essential since metastatic confirmation at this site (N3 disease) might upstage patients. Consequently, the supraclavicular region is an interesting area for pulmonologists and it is worthwhile to train biopsy skills with the help of US imaging.

With US even very small nodes are identifiable and distinguished very well from surrounding structures in particular great vessels. Their often superficial position is very convenient for sampling under direct ultrasonographic vision. More details on US aspects of supraclavicular nodes, cytological aspirations and images were described more than 10 years ago [50].

Before the appearance of positron emission tomography (PET), supraclavicular nodes were easily missed, not only with physical examination, but also with CT imaging. In $8 \%$ of potentially operable lung cancer patients without palpable nodes, supraclavicular lymph node metastasis was detected with US-guided FNA. This study was performed in an era before PET [51]. The insensitivity of palpation was also demonstrated in a series of 117 patients analysed with palpation, US and CT. The palpable nodes containing metastasis had a mean diameter of $25.2 \mathrm{~mm}$ in contrast to the non-palpable nodes that measured $13.7 \mathrm{~mm}$ [52].

Routine US evaluation of 300 patients with lung cancer analysed with CT revealed enlarged supraclavicular lymph nodes in $19 \%$ of patients, especially in small-cell lung cancer and in patients with N2, N3 or extensive disease. In $5 \%$ of these patients, US-guided FNA proved malignancy [53].

In selected patients with mediastinal involvement on CT, non-palpable supraclavicular metastasis was detected with US-guided FNA in $75.4 \%$ of sampled nodes mea- 

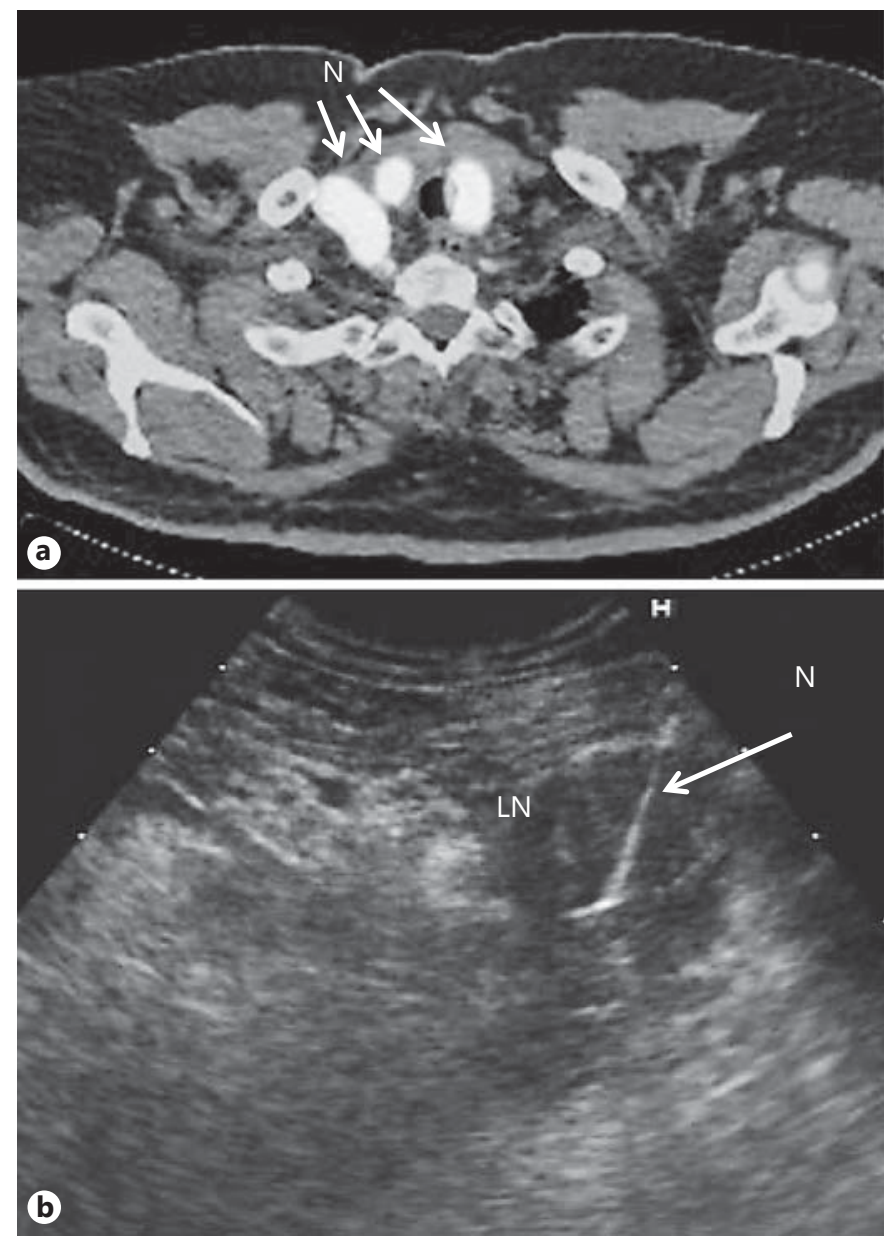

Fig. 7. A TCB from a supraclavicular node containing adenocarcinoma. a PET showing supraclavicular nodes. b US image showing a tissue-core needle (14-gauge) in a right supraclavicular node. LN = Lymph node; $\mathrm{N}=$ needle.

suring at least $5 \mathrm{~mm}$ [54]. Other studies in non-palpable supraclavicular nodes, detected and aspirated with US, confirmed these high rates of metastatic disease in lung cancer but the investigators did not perform PET imaging $[55,56]$.

Supraclavicular metastatic disease is detected with the modern standard imaging technique of PET more accurately. In our own experience, the diagnostic success rate of PET-detected supraclavicular nodes is very high (96\%). Less than half the nodes were found on palpation, obviously presenting a strong argument for the use of image guidance for pathologic sampling [30].

In our experience, patients generally prefer sampling of supraclavicular nodes above endoscopic tests. For diagnosing and staging of lung cancer, US-guided FNA is often appropriate. A major advantage of US guidance, however, is the feasibility to obtain large biopsies with tissue-core needles from relatively small nodes (in our experience from $10 \mathrm{~mm}$ and larger). This provides enough material for histologic diagnoses and molecular analysis of lung cancer (fig. 7).

Initially all supraclavicular nodes in our patients were approached with FNA but as skills evolved over time we started performing TCB in nodes larger than $10 \mathrm{~mm}$ routinely. FNA is chosen for small nodes or when only staging is a requisite. In our practice we sampled supraclavicular nodes in 236 patients, consisting of 186 FNA and 50 TCB (with a 14-gauge needle) complicated by one serious bleeding.

\section{Distant Metastatic Lesions}

The most efficient way to diagnose and stage lung cancer is to sample a metastasis. US is of great help to localize abnormalities found on PET or CT that are suspected for distant metastatic disease. TCB or FNA can be performed under direct vision with US. If not covered by bone, a variety of distant metastases can be sampled with a high chance of diagnostic success including bone metastases with cortical destruction. In our own series of 36 patients with suspected distant metastatic disease based on PETCT imaging, US-guided biopsies failed just once. The great value of US was emphasized by the observation that half of these lesions were impalpable on physical examination [30].

Now that US to guide biopsies in the thorax is becoming more familiar, pulmonologists are supposed to be able to expand their diagnostic activities to other parts of the body and regard all locations of disseminated lung cancer as their working field (fig. 8, 9). This approach will cut diagnostic throughput.

\section{Use of US in Diagnosing Lung Cancer}

The importance of US in the evaluation of lung cancer has been demonstrated by at least two studies. One study from a single centre lung cancer registry showed that $14.4 \%$ of patients were diagnosed with US-guided samples from either pleura, supraclavicular nodes or distant metastatic disease [57]. Another prospective study in patients suspected for thoracic malignancy showed that $13 \%$ of diagnoses were obtained with percutaneous USguided biopsies or aspirations without the need for other invasive tests. All these lesions were first detected with PET-CT and selected on accessibility for percutaneous US-guided sampling [58]. 

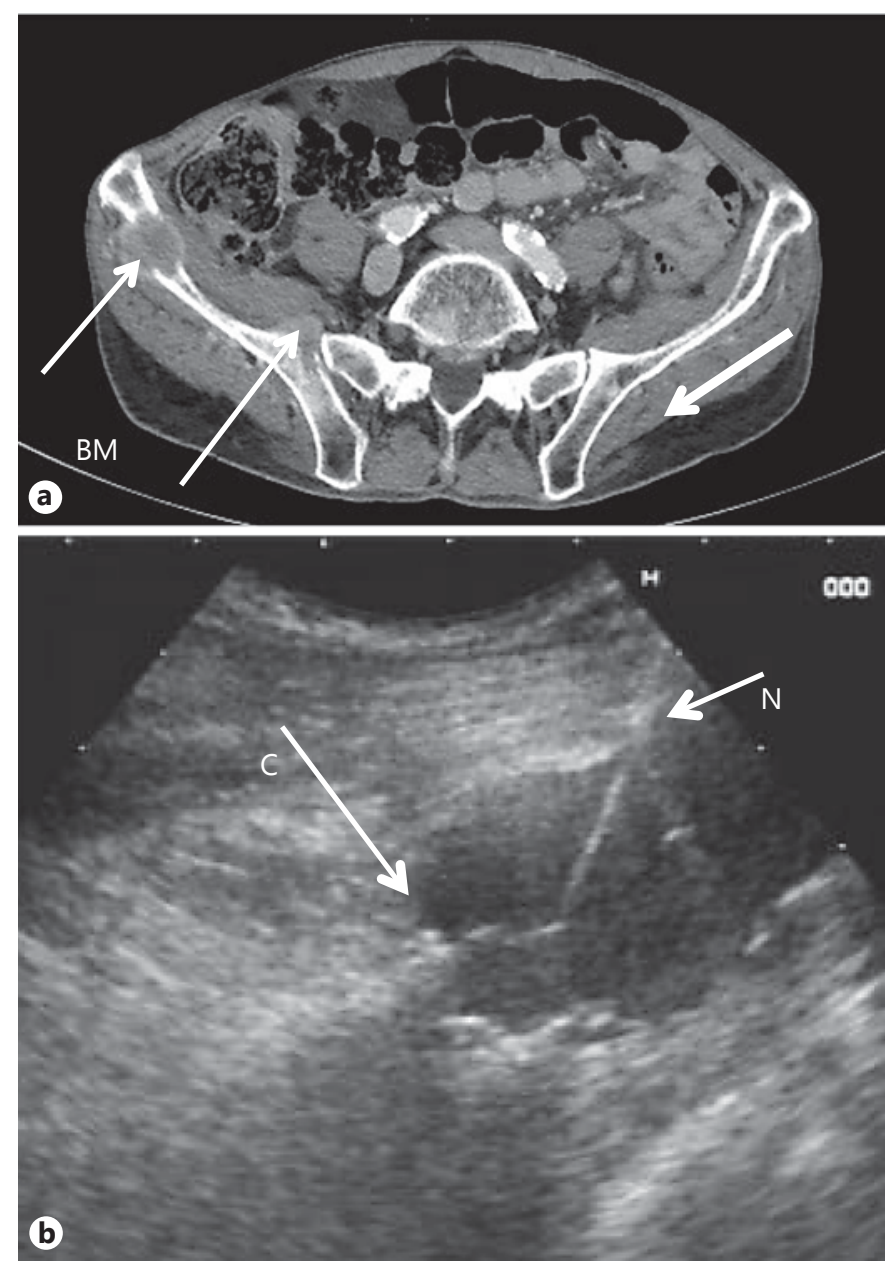

Fig. 8. TCBs from an ossal small-cell lung cancer metastasis. a CT showing two ossal metastases in the right pelvis. $\mathbf{b}$ US image of the most anterior-located metastasis with tissue-core needle and destructed cortex. $\mathrm{BM}=$ Bone metastases; $\mathrm{N}=$ needle; $\mathrm{C}=$ cortex.

Not only is a diagnosis obtained with percutaneous USguided sampling, but the disease stage can also be verified at the same time. Malignant lesions approached percutaneously for US-guided sampling are indeed often metastatic in cases of lung cancer. In 55\% of our own patients, diagnosed after PET-CT and subsequent US-guided sampling, US-guided biopsies determined the disease stage and so precluded further invasive investigations [30].

For treatment decisions, information concerning the type of carcinoma is mandatory nowadays, often requiring immunohistochemical staining as well as molecular analysis. TCBs fulfil these requirements. Histology is the
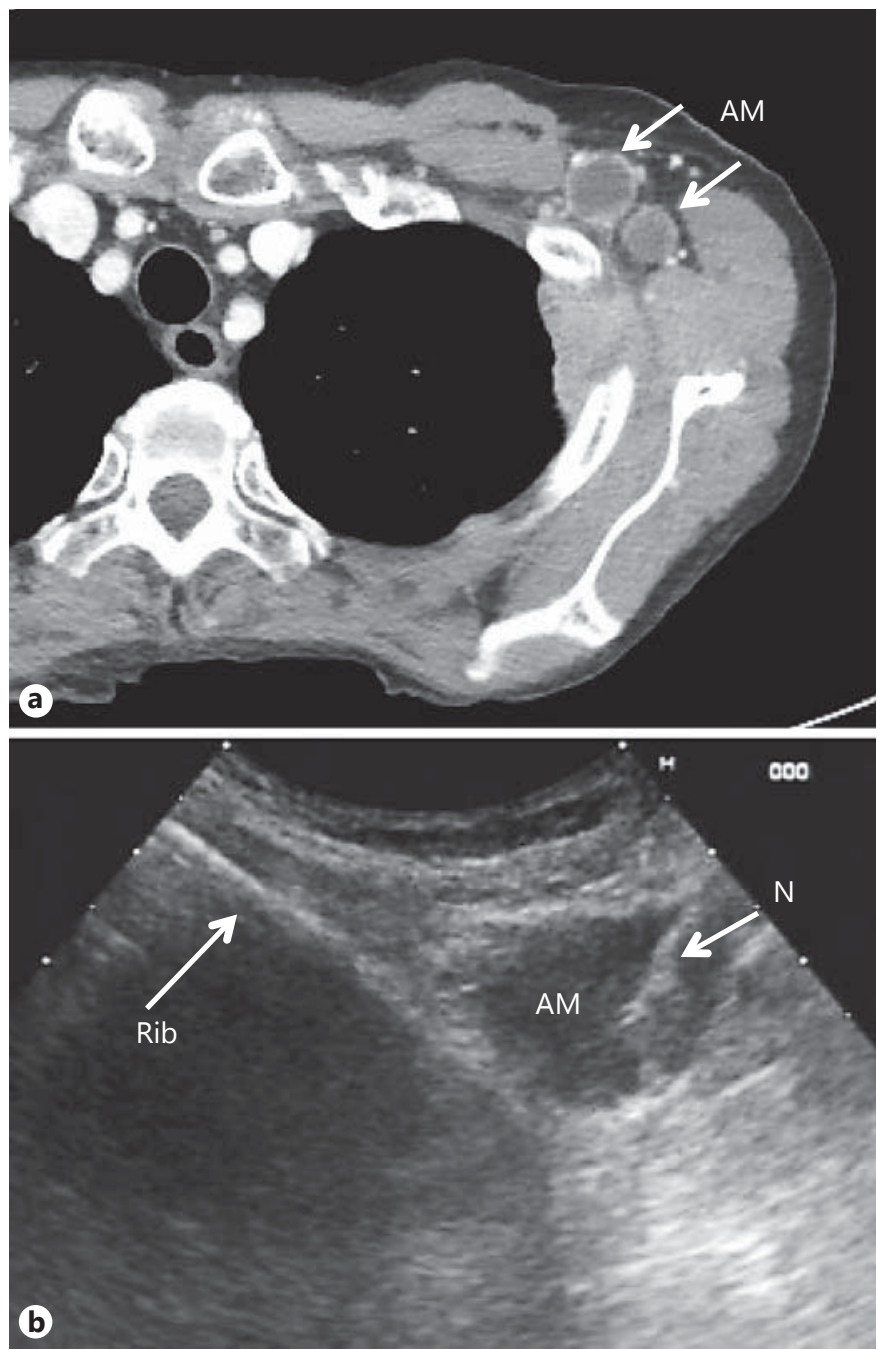

Fig. 9. Metastasis of adenocarcinoma in the left axilla diagnosed with US-guided TCB. a CT showing two axillary metastases (AM). b US image showing a 14-gauge TCB needle $(\mathrm{N})$ introduced in an axillary node.

preferred way to proceed, although aspirates with high numbers of cells in formalin-fixed paraffin embedded tissue blocks will suffice in selected cases.

\section{Education}

The training of pulmonary physicians is important to reduce complications of pleural interventions. A reasonable explanation for the slow incorporation of US in pulmonology is the paucity of training facilities. From a historical perspective, US is performed by interventional ra- 
diologists and there is a lack of crossover of knowledge and skills between different disciplines. The education of pulmonologists is mainly performed by senior pulmonologists in teaching hospitals. Educational facilities should be increased with skilled specialists without mono-disciplinary boundaries.

Educational recommendations were recently updated in the UK by the Royal College of Radiologists. Requirements for three competency levels from basic thoracic US practice up to research development, traineeship and handling of tertiary referrals are described in detail [16]. In addition to this guideline, more approved documents containing educational recommendations for thoracic ultrasonography are listed in a review on safety, risk minimization and training issues in pleural procedures [59]. Optimal contemporary training for pleural procedures should comprise three components: theoretical training, practice on manikins and supervised treatment of patients [59].

Skills can be trained on manikins before being practiced on patients. The Ultrasound-Guided Thoracentesis Skills and Tasks Assessment Test (to measure skill progression) was validated recently and demonstrated that procedural training on phantoms should precede unsupervised thoracentesis on patients [60]. A completely redesigned training system including US-guided thoracentesis on cadaveric models and initial supervision on human interventions reduced a baseline pneumothorax rate from 8.6 to $1.3 \%$ [61].

\section{Conclusion}

Ultrasonography is an indispensable diagnostic tool in pulmonology. For visualisation, sampling and treatment of pleural effusions, US is widely accepted and established in the majority of pulmonology practices. Educational programs have been developed and validated and will help to spread the skill of these day-to-day applications.

Remarkably few pulmonologists use US guidance for biopsies to obtain samples for pathological analysis of chest or chest-associated diseases. Pleural thickenings, pulmonary lesions in contact with the pleura, mediastinal tumours and lesions in the chest wall are within the working field of pulmonologists. Subsequently, it is a small step to apply this technique for metastatic disease in primary pulmonary tumours. The diagnostic success of FNA or TCB under direct US vision is very high, it is easy to learn and safe even in small non-palpable lesions.

\section{Financial Disclosure and Conflicts of Interest}

The authors declare no conflict of interest.

\section{References}

1 Gompelmann D, Herth FJ: Role of endobronchial and endoscopic ultrasound in pulmonary medicine. Respiration 2014;87:3-8.

2 Kreuter M, Mathis G: Emergency ultrasound of the chest. Respiration 2014;87:89-97.

-3 Reissig A, Copetti R: Lung ultrasound in community-acquired pneumonia and in interstitial lung diseases. Respiration 2014;87:179189.

4 Koegelenberg CF, von Groote-Bidlingmaier F, Bolliger CT: Transthoracic ultrasonography for the respiratory physician. Respiration 2012;84:337-350.

5 Koenig SJ, Narasimhan M, Mayo PH: Thoracic ultrasonography for the pulmonary specialist. Chest 2011;140:1332-1341.

6 Lyn-Kew KE, Koenig SJ: Bedside ultrasound for the interventional pulmonologist. Clin Chest Med 2013;34:473-485.

7 Smargiassi A, Inchingolo R, Soldati G, et al: The role of chest ultrasonography in the management of respiratory diseases: document II. Multidiscip Respir Med 2013;8:55.
-8 Sperandeo M, Rotondo A, Guglielmi G, Catalano D, Feragalli B, Trovato GM: Transthoracic ultrasound in the assessment of pleural and pulmonary diseases: use and limitations. Radiol Med 2014, Epub ahead of print.

-9 Tsai TH, Yang PC: Ultrasound in the diagnosis and management of pleural disease. Curr Opin Pulm Med 2003;9:282-290.

$\checkmark 10$ Zanforlin A, Giannuzzi R, Nardini S, et al: The role of chest ultrasonography in the management of respiratory diseases: document I. Multidiscip Respir Med 2013;8:54.

11 Bugalho A, Ferreira D, Dias SS, et al: The diagnostic value of transthoracic ultrasonographic features in predicting malignancy in undiagnosed pleural effusions: a prospective observational study. Respiration 2014;87: 270-278.

12 Qureshi NR, Rahman NM, Gleeson FV: Thoracic ultrasound in the diagnosis of malignant pleural effusion. Thorax 2009;64:139-143.
13 McLoud TC, Flower CD: Imaging the pleura: sonography, CT, and MR imaging. AJR Am J Roentgenol 1991;156:1145-1153.

-14 Kearney SE, Davies CW, Davies RJ, Gleeson FV: Computed tomography and ultrasound in parapneumonic effusions and empyema. Clin Radiol 2000;55:542-547.

15 Wu RG, Yang PC, Kuo SH, Luh KT: 'Fluid color' sign: a useful indicator for discrimination between pleural thickening and pleural effusion. J Ultrasound Med 1995;14:767769 .

16 The Royal College of Radiologists: Ultrasound Training Recommendations for Medical and Surgical Specialties, ed 2. London, Royal College of Radiologists, 2012.

-17 Eibenberger KL, Dock WI, Ammann ME, Dorffner R, Hormann MF, Grabenwoger F: Quantification of pleural effusions: sonography versus radiography. Radiology 1994;191: 681-684. 
18 Vignon P, Chastagner C, Berkane V, et al: Quantitative assessment of pleural effusion in critically ill patients by means of ultrasonography. Crit Care Med 2005;33:1757-1763.

19 Roch A, Bojan M, Michelet P, et al: Usefulness of ultrasonography in predicting pleural effusions $>500 \mathrm{ml}$ in patients receiving mechanical ventilation. Chest 2005;127:224-232.

-20 Smargiassi A, Inchingolo R, Zanforlin A, Valente S, Soldati G, Corbo GM: Description of free-flowing pleural effusions in medical reports after echographic assessment. Respiration 2013;85:439-441.

-21 Havelock T, Teoh R, Laws D, Gleeson F, BTS Pleural Disease Guideline Group: Pleural procedures and thoracic ultrasound: British Thoracic Society Pleural Disease Guideline 2010. Thorax 2010;65(suppl 2):ii61-ii76.

- 22 Gordon CE, Feller-Kopman D, Balk EM, Smetana GW: Pneumothorax following thoracentesis: a systematic review and metaanalysis. Arch Intern Med 2010;170:332-339.

-23 Diacon AH, Brutsche MH, Soler M: Accuracy of pleural puncture sites: a prospective comparison of clinical examination with ultrasound. Chest 2003;123:436-441.

24 Jones PW, Moyers JP, Rogers JT, Rodriguez RM, Lee YC, Light RW: Ultrasound-guided thoracentesis: is it a safer method? Chest 2003; 123:418-423.

-25 Salamonsen M, Ellis S, Paul E, Steinke K, Fielding D: Thoracic ultrasound demonstrates variable location of the intercostal artery. Respiration 2012;83:323-329.

-26 Salamonsen M, Dobeli K, McGrath D, et al: Physician-performed ultrasound can accurately screen for a vulnerable intercostal artery prior to chest drainage procedures. Respirology 2013;18:942-947.

27 Hooper C, Maskell N, BTS Audit Team: British Thoracic Society national pleural procedures audit 2010. Thorax 2011;66:636-637.

28 Hannan LM, Steinfort DP, Irving LB, Hew M: Direct ultrasound localisation for pleural aspiration: translating evidence into action. Intern Med J 2014;44:50-56.

29 Diacon AH, Theron J, Schubert P, et al: Ultrasound-assisted transthoracic biopsy: fineneedle aspiration or cutting-needle biopsy? Eur Respir J 2007;29:357-362.

-30 Stigt JA, Oostdijk AH, Boers JE, van den Berg JW, Groen HJ: Percutaneous ultrasoundguided biopsies in the evaluation of thoracic tumours after PET-CT: a prospective diagnostic study. Respiration 2012;83:45-52.

-31 Koegelenberg CF, Diacon AH: Image-guided pleural biopsy. Curr Opin Pulm Med 2013;19: 368-373.

-32 Botana-Rial M, Leiro-Fernandez V, RepresasRepresas C, Gonzalez-Pineiro A, Tilve-Gomez A, Fernandez-Villar A: Thoracic ultrasound-assisted selection for pleural biopsy with Abrams needle. Respir Care 2013;58: 1949-1954.
33 Koegelenberg CF, Bolliger CT, Theron J, et al: Direct comparison of the diagnostic yield of ultrasound-assisted Abrams and Tru-Cut needle biopsies for pleural tuberculosis. Tho$\operatorname{rax} 2010 ; 65: 857-862$.

34 Chang DB, Yang PC, Luh KT, Kuo SH, Yu CJ: Ultrasound-guided pleural biopsy with TruCut needle. Chest 1991;100:1328-1333.

35 Heilo A, Stenwig AE, Solheim OP: Malignant pleural mesothelioma: US-guided histologic core-needle biopsy. Radiology 1999;211:657659.

36 Stigt JA, Boers JE, Groen HJ: Analysis of 'dry' mesothelioma with ultrasound guided biopsies. Lung Cancer 2012;78:229-233.

- 37 Diacon AH, Schuurmans MM, Theron J, Schubert PT, Wright CA, Bolliger CT: Safety and yield of ultrasound-assisted transthoracic biopsy performed by pulmonologists. Respiration 2004;71:519-522.

38 Sperandeo M, Filabozzi P, Varriale A, et al: Role of thoracic ultrasound in the assessment of pleural and pulmonary diseases. J Ultrasound 2008;11:39-46.

39 Jeon KN, Bae K, Park MJ, et al: US-guided transthoracic biopsy of peripheral lung lesions: pleural contact length influences diagnostic yield. Acta Radiol 2014;55:295-301.

40 Ikezoe J, Morimoto S, Arisawa J, Takashima S, Kozuka T, Nakahara K: Percutaneous biopsy of thoracic lesions: value of sonography for needle guidance. AJR Am J Roentgenol 1990;154:1181-1185.

-41 Yang PC, Lee YC, Yu CJ, et al: Ultrasonographically guided biopsy of thoracic tumors: a comparison of large-bore cutting biopsy with fine-needle aspiration. Cancer 1992;69: 2553-2560.

42 Sconfienza LM, Mauri G, Grossi F, et al: Pleural and peripheral lung lesions: comparison of US- and CT-guided biopsy. Radiology 2013; 266:930-935.

43 Koegelenberg CF, Bolliger CT, Irusen EM, et al: The diagnostic yield and safety of ultrasound-assisted transthoracic fine-needle aspiration of drowned lung. Respiration 2011; 81:26-31.

44 Cao BS, Wu JH, Li XL, Deng J, Liao GQ: Sonographically guided transthoracic biopsy of peripheral lung and mediastinal lesions: role of contrast-enhanced sonography. J Ultrasound Med 2011;30:1479-1490.

45 Annessi V, Paci M, De Franco S, et al: Diagnosis of anterior mediastinal masses with ultrasonically guided core needle biopsy. Chir Ital 2003;55:379-384.

46 Yang PC, Chang DB, Yu CJ, et al: Ultrasoundguided core biopsy of thoracic tumors. Am Rev Respir Dis 1992;146:763-767.

47 Schubert P, Wright CA, Louw M, et al: Ultrasound-assisted transthoracic biopsy: cells or sections? Diagn Cytopathol 2005;33:233-237.
48 Nasit JG, Patel M, Parikh B, Shah M, Davara $\mathrm{K}$ : Anterior mediastinal masses: a study of 50 cases by fine needle aspiration cytology and core needle biopsy as a diagnostic procedure. South Asian J Cancer 2013;2:7-13.

49 Koegelenberg CF, Diacon AH, Irusen EM, et al: The diagnostic yield and safety of ultrasound-assisted transthoracic biopsy of mediastinal masses. Respiration 2011;81:134-141.

50 Fultz PJ, Harrow AR, Elvey SP, et al: Sonographically guided biopsy of supraclavicular lymph nodes: a simple alternative to lung biopsy and other more invasive procedures. AJR Am J Roentgenol 2003;180:1403-1409.

51 Sihoe AD, Lee TW, Ahuja AT, Yim AP: Should cervical ultrasonography be a routine staging investigation for lung cancer patients with impalpable cervical lymph nodes? Eur J Cardiothorac Surg 2004;25:486-491.

52 van Overhagen H, Brakel K, Heijenbrok MW, et al: Metastases in supraclavicular lymph nodes in lung cancer: assessment with palpation, US, and CT. Radiology 2004;232:75-80.

- 53 Prosch H, Strasser G, Sonka C, et al: Cervical ultrasound (US) and US-guided lymph node biopsy as a routine procedure for staging of lung cancer. Ultraschall Med 2007;28:598603.

54 Kumaran M, Benamore RE, Vaidhyanath R, et al: Ultrasound guided cytological aspiration of supraclavicular lymph nodes in patients with suspected lung cancer. Thorax 2005;60:229-233.

55 Fultz PJ, Feins RH, Strang JG, et al: Detection and diagnosis of nonpalpable supraclavicular lymph nodes in lung cancer at CT and US. Radiology 2002;222:245-251.

56 Kendirlinan R, Ozkan G, Bayram M, et al: Ultrasound guided fine-needle aspiration biopsy of metastases in nonpalpable supraclavicular lymph nodes in lung cancer patients. Multidiscip Respir Med 2011;6:220-225.

57 Hoosein MM, Barnes D, Khan AN, et al: The importance of ultrasound in staging and gaining a pathological diagnosis in patients with lung cancer - a two year single centre experience. Thorax 2011;66:414-417.

58 Stigt JA, Uil SM, Oostdijk AH, Boers JE, van den Berg JW, Groen HJ: A diagnostic program for patients suspected of having lung cancer. Clin Lung Cancer 2012;13:475-481.

59 Wrightson JM, Fysh E, Maskell NA, Lee YC: Risk reduction in pleural procedures: sonography, simulation and supervision. Curr Opin Pulm Med 2010;16:340-350.

60 Salamonsen M, McGrath D, Steiler G, Ware R, Colt H, Fielding D: A new instrument to assess physician skill at thoracic ultrasound, including pleural effusion markup. Chest 2013;144:930-934.

61 Duncan DR, Morgenthaler TI, Ryu JH, Daniels CE: Reducing iatrogenic risk in thoracentesis: establishing best practice via experiential training in a zero-risk environment. Chest 2009;135:1315-1320. 